\title{
Return Rates of Chum Salmon are Affected by Different Timings of Juvenile Release
}

\author{
Yuya kogame and Hayato Saneyoshi \\ Salmon and Freshwater Fisheries Research Institute, Hokkaido Research Organization, 3-373 Kitakashiwagi, \\ Eniwa, Hokkaido 061-1433, Japan
}

Keywords: chum salmon, return rate, SST, release timing

Recently, there has been a decreasing trend in the return rate of late-run chum salmon juveniles released from hatcheries in southern Hokkaido. According to previous studies, return rates are critically affected by high mortality of juveniles along the coast (Healey 1982; Bax 1983; Fukuwaka and Suzuki 2005), which is related to coastal sea surface temperature (SST) and juvenile weight at release (Mayama and Ishida 2003). In the Hokkaido hatchery program, chum salmon are classified into three populations (early-, middle-, and late-run) depending on run timing. Their offspring are released in the corresponding order, and juveniles of each run population experience different coastal environments.

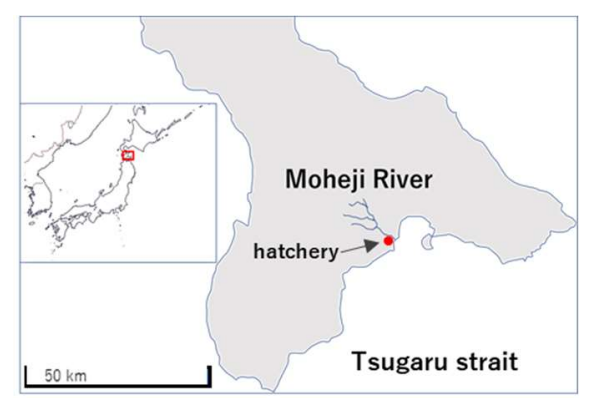

Fig. 1. The location of Moheji river.

We, therefore, hypothesized that coastal environmental conditions faced by late-run juveniles are not optimal. Verifying this hypothesis required analysis of return rates and the coastal environment for each run population. This study aimed to clarify the relationship of each run population's return rate to release timing, weight of juveniles at release, and coastal SST.

To determine return rates, we compared the number of released juveniles and captured returned fish in the Moheji River from 2002 to 2014. We then examined the effects that mean juvenile weight at release, the halfway point of population release (the time at which the number of released fish reached half of the total), and the coastal SST of the Tsugaru Strait exerted on return rates for each run population.

There were no obvious changes in return rates for the early-and middle-run populations over the study period. However, for the late-run population, the return rate decreased. The halfway point of population release had a positive correlation with return rates for early and middle runs (early, $r=0.62, p<0.05$; middle, $r=0.64, p<0.05$ ). On the other hand, for the late run, the halfway point of population release and the coastal SST at that time showed a negative correlation with the return rate (halfway point of population release, $r=-0.75, p<0.05$; coastal SST, $r=-$ $0.68 ; p<0.05)$. Furthermore, the length of the period from the halfway point of population release to the time when the coastal SST exceeded $13^{\circ} \mathrm{C}$ (optimal coastal SST duration) was positively correlated with return rate ( $r=0.83, p$ $<0.05$ ). No correlation was observed between mean weight at release and return rate for any of the three runs.

This study shows that the return rates of late-run populations are affected by the timing of juvenile release and the duration of optimal coastal SST.

\section{REFERENCES}

Bax, N.J. 1983. Early marine mortality of marked juvenile chum salmon (Oncorhynchus keta) released into Hood Canal, Puget Sound, Washington, in 1980. Can. J. Fish. Aquat. Sci. 40: 426-435.

Fukuwaka, M., and T. Suzuki. 2005. Early sea mortality of mark-recaptured juvenile chum salmon in open coastal waters. J. Fish Biol. 60: 3-12.

Healey, M.C. 1982. Timing and relative intensity of size-selective mortality of juvenile chum salmon (Oncorhynchus keta) during early sea life. Can. J. Fish. Aquat. Sci. 39: 952-957.

Mayama, H., and Y. Ishida. 2003. Japanese studies on the early ocean life of juvenile salmon. N. Pac. Anadr. Fish Comm. Bull. 3: 41-67. (Available at https://npafc.org) 